\title{
Synthesis and Properties of Cholesteryl 4-(Alkanoylamino)benzoates: Liquid Crystals and Organogelators
}

\author{
Kanji Kubo $^{1 *}$, Kazuki Tsuji ${ }^{2}$, Akira Mori ${ }^{3}$ and Seiji Ujiie ${ }^{4}$ \\ ${ }^{1}$ Department of Life Science and Technology, Faculty of Engineering, Hokkai-Gakuen University (Asahimachi, Toyohira-ku, Sapporo 062-8605, \\ JAPAN) \\ ${ }^{2}$ Graduate School of Engineering Sciences, 39, Kyushu University (Kasuga-koen, Kasuga, Fukuoka 816-8580, JAPAN) \\ ${ }^{3}$ Institute for Materials Chemistry and Engineering, Kyushu University (Kasuga-koen, Kasuga, Fukuoka 816-8580, JAPAN) \\ ${ }^{4}$ Department of Applied Chemistry, Faculty of Engineering, Oita University (Dannoharu, Oita 870-1192, JAPAN)
}

\begin{abstract}
As a new liquid crystal and organogelator, cholesteryl 4-(alkanoylamino)benzoates were prepared. Cholesteryl 4-(alkanoylamino)benzoates had enantiotropic cholesteric and chiral smectic $\mathrm{C}$ phases. Furthermore cholesteryl 4-(alkanoylamino)benzoates gelled organic liquid such as 1-decanol, linalool, geraniol, nerol, citronellol, linalyl acetate, lavender oil, orange oil, and rose oil. The terpene and perfume gels show good release characteristics of the volatile components for a long period.
\end{abstract}

Key words: liquid crystals, organogelators, chiral smectic $\mathrm{C}$ phase, cholesteric phase, terpenes

\section{INTRODUCTION}

Self-assembled systems are of great importance, particularly for their potential application to nanomaterials such as liquid crystals and gelators ${ }^{1-4)}$. Many studies have been reported on their structure and mechanism of molecular aggregation. More than 110,000 liquid crystalline compounds are reported till now ${ }^{5}$. To design a liquid crystal molecule with mesomorphic properties, a rigid core and flexible alkyl side chains are required ${ }^{6)}$. The number of organogelators has rapidly increased over the last 20 years $^{1-3)}$. In the past, new organogelators were often discovered accidentally, and the studies were dedicated to understanding the relationship between the structure of a gelator and its gelation behavior. The aggregation of organogelators into fibrous networks is driven by multiple weak interactions such as dipole-dipole, van der Waals, hydrogen-bonding, and $\pi$-stacking interactions. Gelators are commonly classified by their driving force for molecular aggregation: nonhydrogen-bond-based and hydrogen-bond-based gelators. Amide compounds (such as amino acid and urea) and hydroxy compounds (such as 12-hydroxystearic acid and sugars) are hydrogen-bond-based gelators, whereas anthracene, cholesterol, and tropone derivatives are nonhydrogen-bond-based gelators. Recently, we have reported several liquid crystalline organogelators called "organogelling Liquid Crystal(LC)" ${ }^{7-10)}$. Several organogelling LCs, octa-alkoxy-substituted $\alpha$-diketonato copper complex ${ }^{11)}$, octa (dodecyl) tetrapyrazinoporphyrazine ${ }^{12}$, 3,4,5-trialkoxybenzoylamines ${ }^{13)}, 2$ - (3,4,5-trialkoxybenzoylamino) -5-cyanotropones ${ }^{14)}, 2,2^{\prime}$-di (3,4,5-trialkoxybenzoylamino) $-5,5^{\prime}$-bitropones ${ }^{9)}$, cholesteryl 4 -alkoxybenzoates $(2)^{7)}$, cholesteryl alkanoates, 4-cyanophenyl 4- $n$-alkoxybenzoates, 4-cyano-4'-alkoxybiphenyls, 4,4'-dialkanoyloxybiphenyls, azoxybenzene derivatives, and 2,3,6,7,10,11-hexaalkoxytriphenylenes ${ }^{10)}$ and so on have been reported. Compounds (2) exhibit enantiotropic cholesteric and smectic A phases and gelled organic solvents such as 1-decanol and n-hexadecane. However, 2 could not be used for gel preparation at low concentration. In this paper, we report the mesomorphic and gelation properties of cholesteryl 4-(alkanoylamino) benzoates (1) as the new organogelling LCs with a cholesteryl benzoate and hydrogen-bonding groups and its application to terpene and perfume gels.

\section{EXPERIMENTAL PROCEDURES}

\subsection{Analysis}

The elemental analyses were performed at the elemental analysis laboratory of Kyushu University, Japan. The melting points were obtained using a Yanagimoto micromelting-point apparatus. The NMR spectra were recorded

\footnotetext{
*Correspondence to: Kanji Kubo, Department of Life Science and Technology, Faculty of Engineering, Hokkai-Gakuen University, Asahimachi, Toyohira-ku, Sapporo 062-8605, JAPAN

E-mail: kubo@Ist.hokkai-s-u.ac.jp

Accepted December 6, 2013 (recieved for review October 1, 2013)

Journal of Oleo Science ISSN 1345-8957 print / ISSN 1347-3352 online

http://www.jstage.jst.go.jp/browse/jos/ http://mc.manusriptcentral.com/jjocs
} 


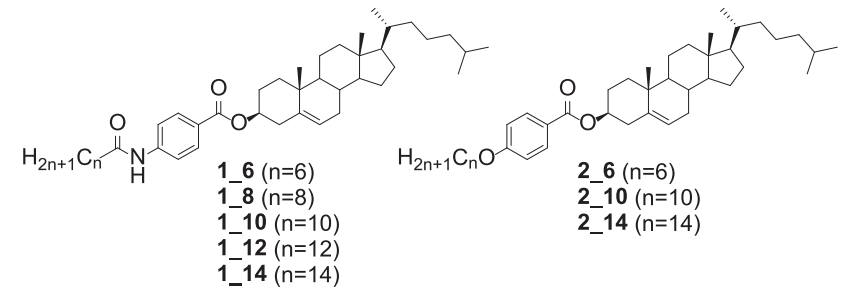

Fig. 1 Chemical structures of $\mathbf{1}$ and $\mathbf{2}$.

using a JEOL GSX-270 spectrometer and in $\mathrm{CDCl}_{3}$ solutions at room temperature; the chemical shifts are expressed in $\delta$ (ppm). The transition temperatures were measured by differential scanning calorimetry (Seiko DSC 6200) and the mesomorphic phases were observed using polarizing optical microscopy (Olympus BHSP BH-2 equipped with a Linkam TH-600MS hot stage). The X-ray diffraction (XRD) measurements were carried out using a Rigaku Rint 2100 system with $\mathrm{Ni}$-filtered $\mathrm{Cu}-\mathrm{K} \alpha$ radiation at various temperatures. The measuring temperatures were controlled using a Linkam HFS-91 hot stage.

\subsection{Synthesis of 1}

A mixture of 4-(hexanoylamino) benzoic acid (0.199 g, $0.799 \mathrm{mmol})$, cholesterol (0.508 g, $1.31 \mathrm{mmol})$, 1-ethyl-3(3-dimethylaminopropyl) carbodiimide hydrochloride $(\mathrm{EDC} \cdot \mathrm{HCl})(0.175 \mathrm{~g}, 0.914 \mathrm{mmol})$, and 4-dimethylaminopyridine (DMAP) (0.139 g, $1.14 \mathrm{mmol})$ in THF (10 mL) was stirred at room temperature for $12 \mathrm{~h}$. The mixture was poured into water, and the organic substance was extracted with chloroform. The organic layer was dried over $\mathrm{Na}_{2} \mathrm{SO}_{4}$ and evaporated in vacuo. The residue was chromatographed on a silica-gel column using chloroform as the eluent to afford crystals, which were recrystallized with hexane/ethyl acetate $(1: 2 v / v)$ to afford 1_6 as colorless crystals $(0.219 \mathrm{~g}, 44 \%$ yield $)$.

1_6(44\%). ${ }^{1} \mathrm{H} \mathrm{NMR}\left(270 \mathrm{MHz}, \mathrm{CDCl}_{3}\right) \delta=0.70(3 \mathrm{H}, \mathrm{s}), 0.87$ $(3 \mathrm{H}, \mathrm{d}, J=6.6 \mathrm{~Hz}), 0.88(3 \mathrm{H}, \mathrm{d}, J=6.6 \mathrm{~Hz}), 0.94(3 \mathrm{H}, \mathrm{d}, J=$ $6.3 \mathrm{~Hz}), 1.08(3 \mathrm{H}, \mathrm{s}), 0.87-2.02(37 \mathrm{H}, \mathrm{m}), 2.39(2 \mathrm{H}, \mathrm{t}, J=7.6$ $\mathrm{Hz}), 2.47(2 \mathrm{H}, \mathrm{d}, J=7.9 \mathrm{~Hz}), 4.85(1 \mathrm{H}, \mathrm{m}), 5.43(1 \mathrm{H}, \mathrm{d}, J=$ $4.6 \mathrm{~Hz}), 7.25(1 \mathrm{H}, \mathrm{s}), 7.60(2 \mathrm{H}, \mathrm{d}, J=8.8 \mathrm{~Hz})$, and $8.01(2 \mathrm{H}$, d, $J=8.8 \mathrm{~Hz}$ ). IR (KBr)v : 1467, 1537, 1601, 1680, 1713, 28, 2934, $3339 \mathrm{~cm}^{-1}$. Found: C, 79.54; H, 10.24; N, $2.34 \%$. Calcd for $\mathrm{C}_{41} \mathrm{H}_{63} \mathrm{NO}_{3}$ : C, 79.69; H, 10.28; N, 2.27\%.

1_8(30\%). ${ }^{1} \mathrm{H}$ NMR $\left(270 \mathrm{MHz}, \mathrm{CDCl}_{3}\right) \delta=0.69(3 \mathrm{H}, \mathrm{s}), 0.86$ $(3 \mathrm{H}, \mathrm{d}, J=6.9 \mathrm{~Hz}), 0.87(3 \mathrm{H}, \mathrm{d}, J=6.9 \mathrm{~Hz}), 0.92(3 \mathrm{H}, \mathrm{d}, J=$ $6.6 \mathrm{~Hz}), 1.06(3 \mathrm{H}, \mathrm{s}), 0.85-2.04(41 \mathrm{H}, \mathrm{m}), 2.38(2 \mathrm{H}, \mathrm{t}, J=7.6$ $\mathrm{Hz}), 2.45(2 \mathrm{H}, \mathrm{d}, J=7.6 \mathrm{~Hz}), 4.83(1 \mathrm{H}, \mathrm{m}), 5.41(1 \mathrm{H}, \mathrm{d}, J=$ $4.0 \mathrm{~Hz}), 7.29(1 \mathrm{H}, \mathrm{s}), 7.59(2 \mathrm{H}, \mathrm{d}, J=8.9 \mathrm{~Hz})$ and $8.00(2 \mathrm{H}, \mathrm{d}$, $J=8.9 \mathrm{~Hz}$ ). Found: C, 79.90; H, 10.50; N, 2.17\%. Calcd for $\mathrm{C}_{43} \mathrm{H}_{67} \mathrm{NO}_{3}$ : C, 79.95; H, 10.45; N, $2.17 \%$.

1_10 (37\%). ${ }^{1} \mathrm{H}$ NMR $\left(270 \mathrm{MHz}, \mathrm{CDCl}_{3}\right) \delta=0.69(3 \mathrm{H}, \mathrm{s})$, $0.86(3 \mathrm{H}, \mathrm{d}, J=6.6 \mathrm{~Hz}), 0.87(3 \mathrm{H}, \mathrm{d}, J=6.4 \mathrm{~Hz}), 0.92(3 \mathrm{H}, \mathrm{d}$, $J=6.3 \mathrm{~Hz}), 1.06(3 \mathrm{H}, \mathrm{s}), 0.85-2.04(45 \mathrm{H}, \mathrm{m}), 2.38(2 \mathrm{H}, \mathrm{t}, J=$ $7.3 \mathrm{~Hz}), 2.45(2 \mathrm{H}, \mathrm{d}, J=7.6 \mathrm{~Hz}), 4.83(1 \mathrm{H}, \mathrm{m}), 5.41(1 \mathrm{H}, \mathrm{d}$,
$J=4.6 \mathrm{~Hz}), 7.30(1 \mathrm{H}, \mathrm{s}), 7.59(2 \mathrm{H}, \mathrm{d}, J=8.6 \mathrm{~Hz})$, and 8.00 $(2 \mathrm{H}, \mathrm{d}, J=8.6 \mathrm{~Hz})$. Found: C, 79.32; H, 10.59; N, $2.06 \%$. Calcd for $\mathrm{C}_{45} \mathrm{H}_{71} \mathrm{NO}_{3} \cdot 0.5 \mathrm{H}_{2} \mathrm{O}: \mathrm{C}, 79.13 ; \mathrm{H}, 10.62 ; \mathrm{N}, 2.08 \%$. 1_12(24\%). ${ }^{1} \mathrm{H} \operatorname{NMR}\left(270 \mathrm{MHz}, \mathrm{CDCl}_{3}\right) \delta=0.69(3 \mathrm{H}, \mathrm{s})$, $0.86(6 \mathrm{H}, \mathrm{d}, J=6.9 \mathrm{~Hz}), 0.92(3 \mathrm{H}, \mathrm{d}, J=6.6 \mathrm{~Hz}), 1.07(3 \mathrm{H}$, s), $0.85-2.05(49 \mathrm{H}, \mathrm{m}), 2.38(2 \mathrm{H}, \mathrm{t}, J=7.3 \mathrm{~Hz}), 2.45(2 \mathrm{H}, \mathrm{d}$, $J=7.6 \mathrm{~Hz}), 4.83(1 \mathrm{H}, \mathrm{m}), 5.41(1 \mathrm{H}, \mathrm{d}, J=4.9 \mathrm{~Hz}), 7.23(1 \mathrm{H}$, s), $7.59(2 \mathrm{H}, \mathrm{d}, J=8.6 \mathrm{~Hz})$, and $8.00(2 \mathrm{H}, \mathrm{d}, J=8.6 \mathrm{~Hz})$. Found: C, 79.35; H, 10.64; N, 1.95\%. Calcd for $\mathrm{C}_{47} \mathrm{H}_{75} \mathrm{NO}_{3}$ : C, 79.30; H, 10.77; N, 1.97\%.

1_14(61\%). ${ }^{1} \mathrm{H} \operatorname{NMR}\left(270 \mathrm{MHz}, \mathrm{CDCl}_{3}\right) \delta=0.69(3 \mathrm{H}, \mathrm{s})$, $0.88(3 \mathrm{H}, \mathrm{d}, J=6.6 \mathrm{~Hz}), 0.89(3 \mathrm{H}, \mathrm{d}, J=6.6 \mathrm{~Hz}), 0.94(3 \mathrm{H}, \mathrm{d}$, $J=6.3 \mathrm{~Hz}), 1.06(3 \mathrm{H}, \mathrm{s}), 0.86-2.04(53 \mathrm{H}, \mathrm{m}), 2.39(2 \mathrm{H}, \mathrm{t}, J$ $=7.6 \mathrm{~Hz}), 2.47(2 \mathrm{H}, \mathrm{d}, J=7.9 \mathrm{~Hz}), 4.85(1 \mathrm{H}, \mathrm{m}), 5.43(1 \mathrm{H}$, $\mathrm{d}, J=4.6 \mathrm{~Hz}), 7.25(1 \mathrm{H}, \mathrm{s}), 7.60(2 \mathrm{H}, \mathrm{d}, J=8.7 \mathrm{~Hz})$, and $8.01(2 \mathrm{H}, \mathrm{d}, J=8.7 \mathrm{~Hz})$. Found: C, 80.29; H, 10.83; N, $1.99 \%$. Calcd for $\mathrm{C}_{47} \mathrm{H}_{75} \mathrm{NO}_{3}$ : C, 80.60; H, 10.91; N, $1.92 \%$.

\subsection{Gelation of Organic Liquids with 1}

Compound 1 (100 mg)was weighed accurately into a screw cap vial. An organic liquid $(1.0 \mathrm{~mL})$ ( $n$-hexane, $n$ decane, $n$-hexadecane, methanol, ethanol, 1-decanol, ethyl acetate, acetonitrile, or tetrahydrofuran) was added. The screw cap of the vial was closed and heated at $120^{\circ} \mathrm{C}$ until a clear solution was obtained. The vial was left at $25^{\circ} \mathrm{C}$ in an incubator for $1 \mathrm{~h}$. The gelation was considered successful when upon inversion no fluid runs down the walls of the vial.

\subsection{Preparation of Terpene and Perfume Gels and Re- lease Test of Volatile Components}

Cholesteryl 4-(tetradecanoylamino) benzoate (1_14) (30.1-32.7 mg) was weighed into a screw cap vial. Terpene (1.0 mL) (linalool, geraniol, nerol, citronellol, or linalyl acetate) or an essential oil (lavender oil, orange oil, or rose oil) was added. The screw cap of the vial was closed and heated at $120^{\circ} \mathrm{C}$ until a clear solution was obtained. The vial was left at $25^{\circ} \mathrm{C}$ in an incubator for $1 \mathrm{~h}$ The release tests of the volatile components from 1_14-linalool, lavender oil, orange oil, and rose oil gels were conducted. The caps of the glass tubes containing the fragrance gel were opened. They were left at room temperature (temperature range: $13.2-29.3^{\circ} \mathrm{C}$, average temperature: $22.6^{\circ} \mathrm{C}$ ) and their weights were measured after 50, 100, and 200 days.

\section{RESULTS AND DISCUSSION}

\subsection{Synthesis of 1}

Compounds 1 were prepared by the esterification of cholesterol with the corresponding 4-(alkanoylamino) benzoic acid in the presence of EDC $\cdot \mathrm{HCl}$ and DMAP. The structures and purities of 1 were established by the NMR spectral and elemental analyses. 


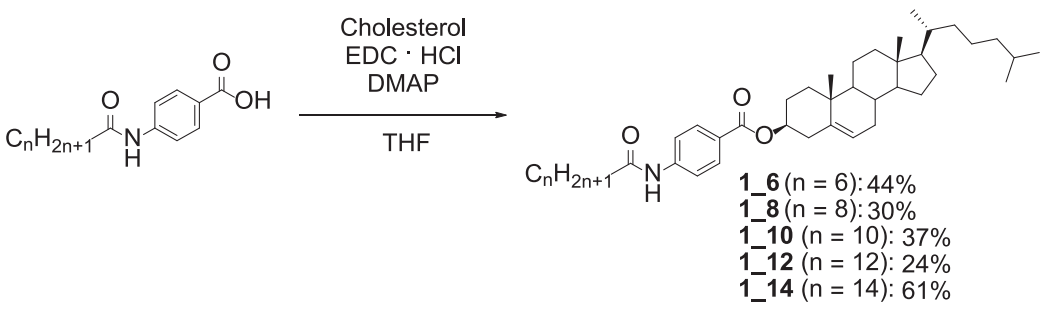

Scheme 1

\subsection{Mesomorphic Properties}

The transition temperatures and thermal behaviors of the 1 were determined using a differential scanning calorimeter, a polarizing microscope equipped with a hot stage, and an XRD study. The optical micrographs of cholesteric $\left(\mathrm{N}^{*}\right)$ of 1_12 and chiral smectic $\mathrm{C}\left(\mathrm{SmC}^{*}\right)$ phases of 1_14 are shown in Fig. 2. Chiral smectic $\mathrm{C}$ and cholesteric phases were determined from a following observation and XRD study, i.e., broken focal-conic fan, banded focal-conic fan, and schlieren textures for chiral smectic C phase ${ }^{15)}$;
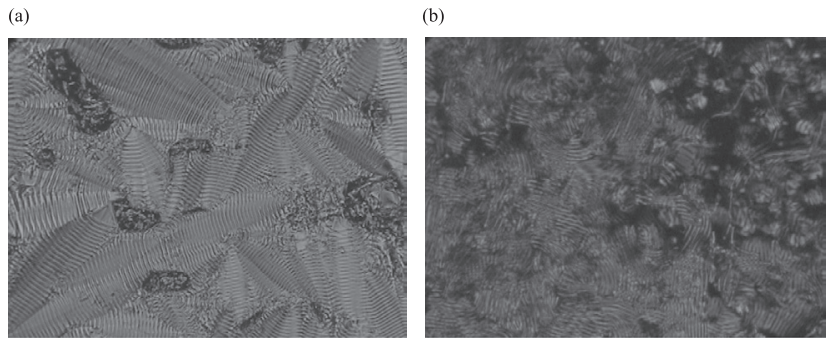

Fig. 2 Optical cross-polarizing microsgraphs of 1_14 at (a) $180^{\circ} \mathrm{C}\left(\mathrm{SmC}^{*}\right)$ and (b) $1 \_12$ at $230^{\circ} \mathrm{C}\left(\overline{\mathrm{N}}^{*}\right)$. All pictures taken on cooling from the isotropic phase. fingerprint texture, Grandjean steps at the border and oily streak textures for the cholesteric phase. The thermal behaviors of the cholesteryl benzoates ( 1 and 2 ) are summarized in Table 1. Compounds 1 had a phase sequence of Cr-SmC ${ }^{*}-\mathrm{N}^{*}$-Isotropic (Iso), whereas 2 had a phase sequence of $\mathrm{Cr}-\mathrm{SmA}-\mathrm{N}^{*}$-Iso. The melting and clearing points of 1 were higher than those of the corresponding derivatives 2 , showing that the hydrogen bonds of the amide group strengthen the intermolecular interactions.

We measured the XRD pattern of the mesophases. The smectic layer spacings $(d)$ and molecular lengths $(l)$ of 1 are listed in Table 2. The molecular lengths $(l)$ of 1 were calculated by the MM2 method. The $d / l$ ratios of chiral smectic $\mathrm{C}\left(\mathrm{SmC}^{*}\right)$ phase of 1 are within the range $0.71-0.77$, showing that the molecular long axes of 1 are tilted with respect to the normal to the layer in the $\mathrm{SmC}^{*}$ phase and form the layer as shown in Fig. 3.

\subsection{Gelation Properties}

We carried out the gelation test of 1 in various organic solvents ( $n$-hexane, $n$-decane, $n$-hexadecane, methanol, ethanol, 1-decanol, ethyl acetate, acetonitrile, and tetrahydrofuran). The result of gelation test with 1 is shown in Table 3 . Compounds 1 could not gel $n$-hexane, $n$-decane,

Table 1 Transition temperatures $\left({ }^{\circ} \mathrm{C}\right)$ of $\mathbf{1}$ and $\mathbf{2}$.

\begin{tabular}{|c|c|c|}
\hline & \multicolumn{2}{|c|}{ Transition Temperatures $/{ }^{\circ} \mathrm{C}$} \\
\hline & 1 & 2 \\
\hline -6 $(n=6)$ & $\mathrm{Cr} \cdot 195.9 \cdot \mathrm{N}^{*} \cdot 252.9 \cdot$ Iso & $\mathrm{Cr}_{1} \cdot 113.5 \cdot \mathrm{Cr}_{2} \cdot 150.9 \cdot \mathrm{N}^{*} \cdot 229.9 \cdot$ Iso \\
\hline $\mathbf{8}(\mathrm{n}=8)$ & $\mathrm{Cr}_{1} \cdot 109.8 \cdot \mathrm{Cr}_{2} \cdot 209.1 \cdot \mathrm{SmC}^{*} \cdot 226.7 \cdot \mathrm{N}^{*} \cdot 249.6 \cdot$ Iso & \\
\hline _10 $(\mathrm{n}=10)$ & $\mathrm{Cr} \cdot 203.3 \cdot \mathrm{SmC}^{*} \cdot 223.2 \cdot \mathrm{N}^{*} \cdot 242.7 \cdot$ Iso & $\mathrm{Cr} \cdot 110.4 \cdot \mathrm{SmA} \cdot 177.7 \cdot \mathrm{N}^{*} \cdot 208.1 \cdot$ Iso \\
\hline $12(\mathrm{n}=12)$ & $\mathrm{Cr}_{1} \cdot 170.4 \cdot \mathrm{Cr}_{2} \cdot 175.5 \cdot \mathrm{SmC}^{*} \cdot 228.8 \cdot \mathrm{N}^{*} \cdot 235.8 \cdot$ Iso & \\
\hline _14 $(\mathrm{n}=14)$ & $\mathrm{Cr} \cdot 138.3 \cdot \mathrm{SmC}^{*} \cdot 191.8 \cdot \mathrm{N}^{*} \cdot 215.0 \cdot$ Iso & $\mathrm{Cr} \cdot 117.6 \cdot \mathrm{SmA} \cdot 175.9 \cdot \mathrm{N}^{*} \cdot 190.2 \cdot$ Iso \\
\hline
\end{tabular}

Table 2 Layer spacings $(\AA)$, molecular lengths $(\AA), d / l$ values, and tilt angles $\left({ }^{\circ}\right)$ of $\mathbf{1}$.

\begin{tabular}{|c|c|c|c|c|c|}
\hline \multirow{2}{*}{ Compounds } & \multicolumn{2}{|c|}{ X-Ray Diffraction } & \multirow{2}{*}{$\begin{array}{c}\text { Molecular Lengths }(l) \\
\qquad / \AA\end{array}$} & \multirow{2}{*}{$d / l$} & \multirow{2}{*}{ Tilt Angle/ } \\
\hline & Temp. $/{ }^{\circ} \mathrm{C}$ & Layer Spacings $(d) / \AA$ & & & \\
\hline 1_10 & 215 & 29.3 & 37.8 & 0.77 & 40 \\
\hline 1_12 & 200 & 30.4 & 40.3 & 0.75 & 42 \\
\hline 1_14 & 180 & 30.6 & 42.9 & 0.71 & 45 \\
\hline
\end{tabular}



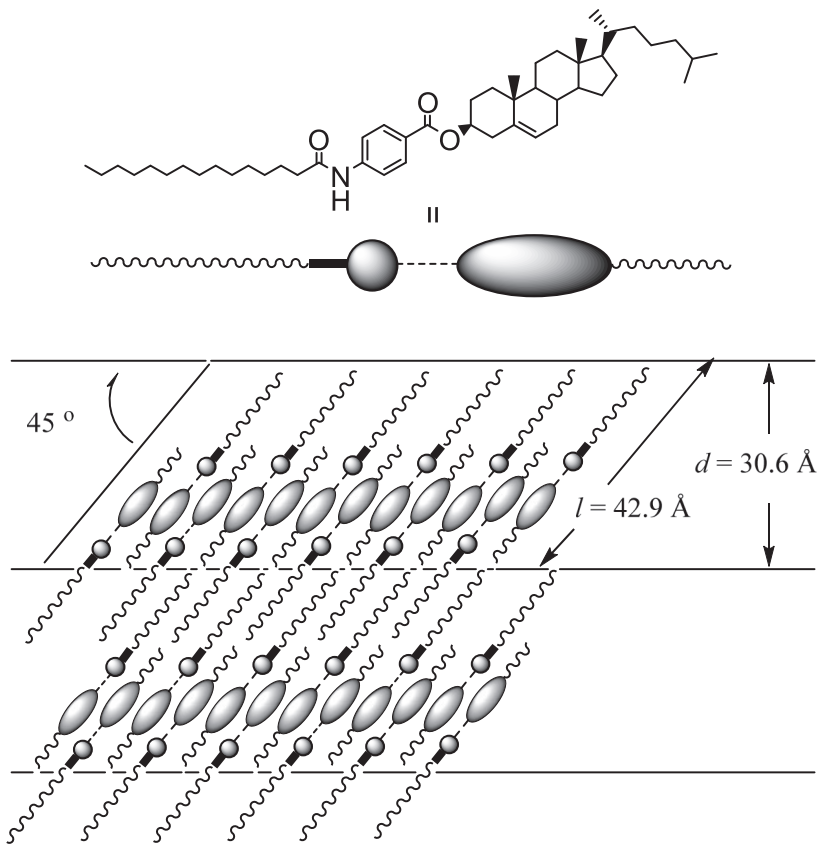

Fig. 3 Packing model of $1 \_14$ in the smectic $C^{*}$ phase.

n-hexadecane, methanol, ethanol, ethyl acetate, acetonitrile, and tetrahydrofuran. Interestingly, 1 showed high gelling selectivity for 1-decanol, while 2 gelled 1-decanol and $n$-hexadecane. Figure 3 shows the photograph of 1_14-decanol gel and an optical micrograph of the gel phase of 1_14 in 1-decanol $(5.0 \mathrm{w} / \mathrm{v} \%)$ recorded at $25^{\circ} \mathrm{C}$ on cooling from an isotropic liquid state. Highly intertwined, rod-like fibers aligned to form the network structures by making bundles with diameters of ca. $0.8-2.0 \mu \mathrm{m}$. The minimum gel concentrations (MGC, g/L) of 1 and 2 are 32 for 1_6, 27 for 1_8, 42 for 1_10, 31 for 1_12, 24 for 1_14, 33 for 2_6, 56 for 2_10, and 62 for 2_14. The gelation ability of 1_14 for 1-decanol is superior than that of the other cholesteryl benzoates.

To investigate the hydrogen bonding in the gels, the IR (a)

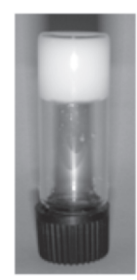

(b)

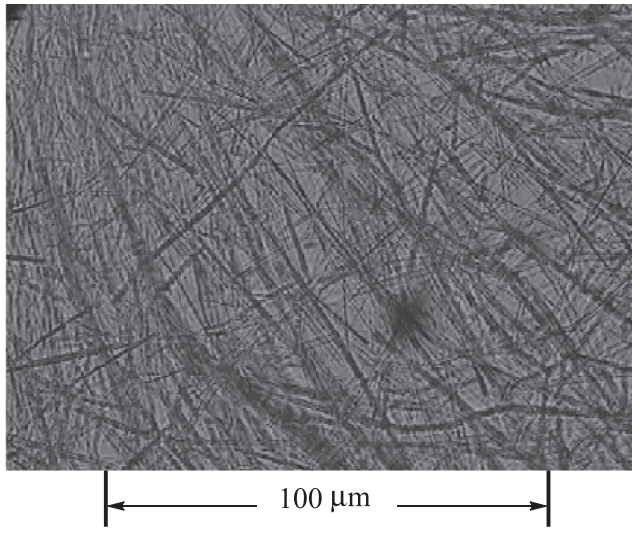

Fig. 4 (a) Photograph and (b) micrograph of 1_14 • 1-decanol gel.

spectra of crystalline, 1-decanol gel $(5.0 \mathrm{w} / \mathrm{v} \%)$, and the chloroform solution of 1_14 were measured. The absorption band at $1679 \mathrm{~cm}^{-1}$ of 1_14-decanol gel was lower than that $\left(1685 \mathrm{~cm}^{-1}\right)$ of the chloroform solution and close to that $\left(1676 \mathrm{~cm}^{-1}\right)$ of the crystalline compound, showing that the intermolecular hydrogen bonds of the amide group play an important role in the crystal and gel states.

\subsection{Preparation of Terpene and Perfume Gels}

To study the application of organogelator 1 to new materials, the terpene and perfume gels were prepared. In perfume, fragrance and deodorant materials, hydrogelators such as carrageenan, agar, collagen, gellan gum, and gelatin have been used for gelations of water-containing terpenes, essential oils, and perfumes. Therefore, the purity of the oils in the gels is low and most of the components of these materials comprise water. Fortunately, under the gel-organic liquid conditions $(30.1-32.7 \mathrm{mg} / 1.0 \mathrm{~mL}), 1 \_14$ could gel the terpenoids such as linalool, geraniol, nerol, citronellol, linalyl acetate and essential oils such as lavender oil, orange oil, rose oil (Fig. 5).

Table 3 Gelation Ability of $\mathbf{1}$.

\begin{tabular}{|c|c|c|c|c|c|}
\hline & 1_6 & 1_8 & 1_10 & 1_12 & 1_14 \\
\hline Hexane & ${ }^{\mathrm{d} I n s o l}$ & dinsol & ${ }^{\mathrm{c}}$ Cryst & ${ }^{\circ}$ Cryst & ${ }^{\mathrm{c}}$ Cryst \\
\hline$n$-Decane & ${ }^{\mathrm{d}}$ Insol & ${ }^{\mathrm{d}}$ Insol & ${ }^{\mathrm{c}}$ Cryst & ${ }^{\mathrm{c}}$ Cryst & ${ }^{\mathrm{c}}$ Cryst \\
\hline$n$-Hexadecane & ${ }^{\mathrm{d}}$ Insol & ${ }^{\mathrm{d}}$ Insol & ${ }^{\mathrm{c}}$ Cryst & ${ }^{\mathrm{c} C}$ Cryst & ${ }^{\mathrm{c}}$ Cryst \\
\hline Methanol & ${ }^{\mathrm{c}}$ Cryst & ${ }^{\mathrm{c}}$ Cryst & ${ }^{\mathrm{c}}$ Cryst & ${ }^{\mathrm{c}}$ Cryst & ${ }^{\mathrm{c}}$ Cryst \\
\hline Ethanol & ${ }^{\mathrm{c}}$ Cryst & ${ }^{\mathrm{c}}$ Cryst & ${ }^{\mathrm{c}}$ Cryst & ${ }^{\mathrm{c}}$ Cryst & ${ }^{\circ}$ Cryst \\
\hline 1-Decanol & ${ }^{\mathrm{a}} \mathrm{Gel}$ & ${ }^{\mathrm{a}} \mathrm{Gel}$ & ${ }^{\mathrm{a}} \mathrm{Gel}$ & ${ }^{\mathrm{a}} \mathrm{Gel}$ & ${ }^{\mathrm{a}} \mathrm{Gel}$ \\
\hline Ethyl acetate & ${ }^{\circ}$ Cryst & ${ }^{\mathrm{c}}$ Cryst & ${ }^{\circ}$ Cryst & ${ }^{\mathrm{c}} \mathrm{Cryst}$ & ${ }^{\mathrm{c}} \mathrm{Cryst}$ \\
\hline Acetonitrile & ${ }^{\mathrm{d}}$ Insol & ${ }^{\mathrm{d}}$ Insol & ${ }^{\mathrm{d}}$ Insol & ${ }^{\mathrm{d}}$ Insol & ${ }^{\mathrm{c}}$ Cryst \\
\hline Tetrahydrofuran & ${ }^{\mathrm{b}} \mathrm{Sol}$ & ${ }^{\mathrm{b}}$ Sol & ${ }^{\mathrm{b}} \mathrm{Sol}$ & ${ }^{\mathrm{b}} \mathrm{Sol}$ & ${ }^{\mathrm{b}} \mathrm{Sol}$ \\
\hline
\end{tabular}

${ }^{a}$ Gel: Gelation, ${ }^{b}$ Sol: Solution, ${ }^{\mathrm{c}}$ Cryst: Crystallization, ${ }^{\mathrm{d}}$ Insol: Insoluble. 
(a)

(b)

(c)

(d)

(e)

(f)

(g)

(h)

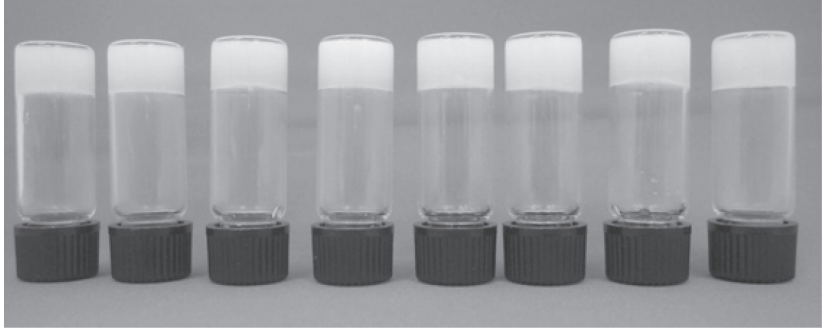

Fig. 5 Photograph of (a) 1_14 $\cdot$ linalool, (b) 1_14 $\cdot$ geraniol, (c) 1_14 $\cdot$ nerol, (d) 1_14 $\cdot$ citronellol, (e) 1_14 $\cdot$ linalyl acetate, (f) 1_14 $\cdot$ lavender oil, (g) 1_14 $\cdot$ orange oil, and (h) 1_14 $\cdot$ rose oil gels.

The release tests of the volatile components from 1_14-linalool, lavender oil, orange oil, and rose oil gels were carried out. The results are shown in Table 4 . The weights of the gels and neat liquids decreased with time. The rate of decrease in the weight of the gels were slower than those of the neat liquids, showing that the gel state controlled the release of the volatile components. After 200 days, each gel maintained the gel state with a characteristic scent of terpenoids and essential oil.

\section{CONCLUSION}

Compounds (1_14) exhibited mesomorphic and organogelation properties with a good gelation ability for terpenes and essential oils. We succeeded in preparing perfume gels containing $96 \%$ or more of terpene and essential oil; the perfume gels showed good release characteristics of the volatile components for a long period. The gels may be utilized as fragrance and deodorant agents.

\section{ACKNOWLEDGMENT}

This work was supported by the funds from HokkaiGakuen and Ministry of Education, Science, Sports and Culture of Japan and performed under the Cooperative Research Program of "Network Joint Research Center for Materials and Devices".

\section{References}

1) Terech, P; Weiss, R. G, Low-Molecular Mass Gelators of Organic Liquids and the Properties of their Gels. Chem. Rev. 97, 3133-3159(1997).

2) Abdallah, D. J.; Weiss, R. G., Organogels and Low Molecular Mass Organic Gelators. Adv. Mater. 12, $1237-$ $1247(2000)$.

3) Hanabusa, K.; Shirai, H., Development of Organogelators: Compounds which Can Harden Oils and Organic Solvents. Hyomen 36, 291-303 (1998).

4) Kubo, K., Syhthesis and Properties of Functional Materials with Troponoid. Oleoscience 9, 561-569 (2009).

5) Vill, V., LiqCryst 5.2 Database of Liquid Crystalline Compounds, Fujitsu Kyushu System Engineering (FQS), Fukuoka (2013).

6) Kubo, K.; Mori, A., Zairyo Yuki Kagaku, M. IYODA ed., Asakura Shoten, Japan, pp. 71-110(2002).

7) Kubo, K; Tsuji, K.; Mori, A.; Ujiie, S., Synthesis and Properties of Cholesteryl Benzoate Derivatives: Liquid Crystals and Organogelators. J. Oleo Sci. 53, 467-470 (2004).

8) Kubo, K., Oil Gelation By Troponoid Liquid Crystals. Kagaku 59, 56-57 (2004).

9) Kubo, K.; Mori, A.; Ujiie, S.; Tschierske, C., Synthesis and Properties of Columnar Liquid Crystals and Organogelator with a Bitropone Core. J. Oleo Sci. 53, 575-579 (2004).

10) Kubo, K.; Takahashi, H.; Takechi, H., Liquid Crystals as Organogelators: Liquid Crystals Gelled Organic Sol-

Table 4 Weight changes (mg) of the perfume gels containing 1_14 by release tests of the volatile components.

\begin{tabular}{lccccc}
\hline \multirow{2}{*}{ Solvents/Status } & \multirow{2}{*}{ 1_14 (mg) } & \multicolumn{4}{c}{ Weight (mg) } \\
\cline { 3 - 6 } & & 0 & after 50d & after 100d & after 200d \\
\hline Linallol/Gel & 30.1 & 877.2 & 838.4 & 811.4 & 732.4 \\
Linallol/Liquid & 0 & 877.3 & 832.5 & 801.0 & 713.8 \\
Lavender Oil/Gel & 32.7 & 962.5 & 922.1 & 899.9 & 850.7 \\
Lavender Oil/Liquid & 0 & 963.0 & 909.1 & 877.5 & 803.6 \\
Rose Oil/Gel & 30.6 & 942.9 & 929.6 & 924.6 & 901.4 \\
Rose Oil/Liquid & 0 & 943.7 & 914.6 & 906.9 & 884.7 \\
Orange Oil/Gel & 30.8 & 852.6 & 418.4 & 212.9 & 195.8 \\
Orange Oil/Liquid & 0 & 853.1 & 397.3 & 144.1 & 117.9 \\
\hline
\end{tabular}


vent. J. Oleo Sci. 55, 545-549(2006).

11) Ohta, K.; Watanabe, T.; Fujimoto, T; Yamamoto, I., Synthesis and Columnar Mesomorphism of Octa(dodecyl) tetrapyrazinoporphyrazine and Its Copper(II) Complex. J. Chem. Soc. Chem. Comm. 1611-1613 (1989).

12) Ohta, K.; Moriya, M.; Ikejima, M; Hasebe, H.; Kobayashi, N.; Yamamoto, I.; Gels of Bis[1,2-bis (3,4-di- $n$-alkoxyphenyl) ethanedione dioximato]-Palladium(II) Complexes. Bull. Chem. Soc. Jpn. 70, 1199-1203 (1997)

13) Beginn, U.; Sheiko, S; Moller, M., Self-organization of
3,4,5-Tris (octyloxy) benzamide in Solution and Embedding of the Aggregates into Methacrylate Resins. Macromol. Chem. Phys. 201, 1008-1015(2000).

14) Hashimoto, M.; Ujiie, S.; Mori, A., Low Molecular Weight Gelators with Hexagonal Order in Their LiquidCrystal Phases and Gel States: 5-Cyano-2-(3,4,5-trialkoxybenzoylamino) tropones. Adv. Mater. 15, 797-800 (2003).

15) Gray, G. W.; Goodby, J. W., Smectic Liquid Crystals Textures and Structures, Leonard Hill, Glasgow and London, pp. 1-22 (1984). 